\title{
STUDY OF CIVIL PROTECTION READINESS IN CASE OF DISASTERS
}

\author{
Vanya Slavova ${ }^{1}$, Veselin Ivanov ${ }^{1}$, Polina Taleva ${ }^{2}$, Veselina Petrova-Tacheva ${ }^{3}$ \\ 1) Department Neurology, Psychiatry and Disaster medicine, Faculty of Medicine, \\ Trakia University,-Stara Zagora, Bulgaria \\ 2) Department Surgery, Neurosurgery, Urology and Anesthesiology, Faculty of \\ Medicine, Trakia University, Stara Zagora, Bulgaria \\ 3) Department Molecular Biology, Immunology and Medical Genetics, Faculty \\ of Medicine, Trakia University, Stara Zagora, Bulgaria.
}

\begin{abstract}
Background: In the long history of the humankind the different by natural and man-made disasters are the common phenomena. They cause the appearance of massive destruction, property damage, environmental catastrophes, large numbers of dead and injured people. The population readiness to behave and act in disasters is essential to reduce the risk of people's life and health. Good preparation ensures effective reaction of protection and assistance to the affected people.

Aim: Research and analysis of knowledge and skills for protection in disasters of people working in various fields of the national economy in Stara Zagora, Republic of Bulgaria.

Materials and methods: An empirical sociological study was conducted through direct group self - administered questionnaire (SAQ) of 322 workers in various fields of the national economy in the Stara Zagora district. The total number of respondents was 350 , of which 322 responded, the response rate is $92 \%$. The survey was conducted from January to December 2016. The places of the study were enterprises and companies in various industries in the Stara Zagora district.

Results: Above the half of the inquired regard their knowledge and skills concerning the protection and providing first aid as insufficient. Training courses occupy a leading place among the preferred ways of acquiring knowledge and skills.

Conclusions: Insufficient public awareness of protection in disaster situations represents a major challenge. There is a need to improve the knowledge and skills about protection in emergency situations by conducting theoretical training and increasing the efficiency of these training
\end{abstract}

Keywords: disaster, civil protection, evacuation, personal protective equipment, early warning and alert in disasters, readiness for disaster protection,

\section{INTRODUCTION}

In the long history of the humankind, the different by natural and man-made disasters are the common phe- nomena. They cause the appearance of massive destruction, property damage, environmental catastrophes, large numbers of dead and injured people. With the emergence of different types, sizes and weight of disasters, it is created a heavy general and medical situation in the region. For a very short period of time, massive irretrievable and medical losses occur in the affected areas, the most vulnerable and injured risk groups being elderly and children [1,2]. The suddenness of occurrence and the sharp disparity between the required and available forces and means to eradicate the arisen consequences requires prior preparation and planning of measures to protect the population and providing medical assistance in the hearth of defeat.

The population readiness to behave and act in disasters is essential to reduce the risk of people's life and health. Good preparation ensures effective reaction of protection and assistance to the affected people.

One of the main policies of the European Union's in humanitarian aid and civil protection. It is conducted by the General Directorate "European Civil Protection and Humanitarian Aid Operations" of the European Commission (ECHO). Through it, the European Union provides assistance to victims of disasters and conflicts around the world and works to prevent humanitarian crises [3, 4]. In accordance with the fundamental values of the European Union - solidarity, respect for human dignity, equality and tolerance, it is taking action to protect human lives, reduces and prevents suffering and protects the integrity and dignity of victims. The various activities of ECHO reflect disasters around the world and the European Union's readiness to play a leading role in providing assistance to victims $[5,6]$. The legal framework for protection in disasters contains a number of international documents and European Union documents. In the European Union, it is created as a mechanism for civil protection. The mechanism is mobilized in case of disaster both within the European Union and beyond. With the mechanism, it is increased European cooperation in the field of civil protection and efforts for the Member States at a national, regional and local level are supported. Effective tools for the prevention, preparation and reaction to the occurrence of natural and 
man-made disasters are provided [7]. The Civil Protection Mechanism of the European Union increases readiness to protect the population of the participating countries in disasters through educational programs, exercises, exchanges of experts and others. European Union provides funding to projects for prevention and preparedness in order to promote scientific research on natural disasters, developing early warning systems and systems for informing the population [8].

At present in Bulgaria, there is a synchronization of the legal framework for protection in disasters with that of the European Union but is not well adapted.

In the Republic of Bulgaria, the readiness of population protection in disasters has not been studied yet. Therefore we did this study in the Stara Zagora district. Clarifying and analyzing the knowledge and skills about conduct and action in disasters will allow defining the level of preparedness to protect its population, to outline trends and solutions for education and training in modern conditions.

The aim of the study was to research knowledge and skills for protection in disasters of people working in various fields of the national economy in Stara Zagora, Republic of Bulgaria. To achieve the goal we set ourselves the following tasks:

1. To explore and analyze the knowledge to conduct evacuation measures in disasters.

2. To explore and analyze the knowledge and skills to use individual and collective measures of protection in disasters.

3. To explore and analyze the knowledge of early warning alerts in case of disasters.

\section{MATERIALS AND METHODS}

An empirical sociological study was conducted through direct group self - administered questionnaire (SAQ) of 322 workers in various fields of the national economy in Stara Zagora district, Bulgaria with a preponderance of manufacturing before the administrative sphere. The total number of respondents was 350, of which 322 responded, the response rate is $92 \%$. The survey was conducted from January to December 2016. The places of the study were enterprises and companies in various industries in Stara Zagora district, some of which from the list of sites of critical infrastructure in Bulgaria. Respondents were working in the fields of energetics, construction, engineering, manufacturing of rubber products and concrete structures.

The data and results presented in this research are part of a broad research study using a standard questionnaire containing 33 questions in seven main areas: the socio-demographic and professional characteristics of the respondents; awareness of the riskiest natural and manmade disasters in Stara Zagora district; acquired knowledge and skills for protection in the event of disasters; acquired knowledge and skills for first aid; sources for acquiring knowledge and skills to protect and provide first-aid medical assistance in disasters; attitudes towards enhancing knowledge and skills for disaster protection and provid- ing first-aid at the hearth of defeat; willingness to participate in workplace action groups and volunteer teams to carry out rescue operations and provide first-aid disaster relief. In the present study were analysed the respondents' answers concerning their knowledge and skills for protection in disasters. The collection of empirical data was performed in compliance with the requirements of anonymity, voluntary participation and non-maleficence in dealing with people. The survey was conducted at an appropriate time for workers, the time and location were agreed in advance and with the cooperation of employers.

For data collection was used statistical package IBM SPSS v.19. Data analysis was conducted applying descriptive statistics methods to summarize quantitative and qualitative variables (absolute frequencies, relative frequencies, cumulative frequencies). Methods of assessment and methods for testing hypotheses $-\mathrm{x}^{2}$ - test, Fisher exact test was used. The critical level of significance was $\alpha=0,05$. The corresponding null hypothesis is rejected when the $\mathrm{P}$ value was less than $\alpha$.

\section{RESULTS}

Knowledge and skills of basic remedies in the event of a disaster is essential to limit the impact of striking factors and saving the lives of people caught in the hearth of the disaster [9].

Effective protection in the event of a disaster is carried out through the following main ways:

- Conducting an evacuation;

- Use of Personal Protective Equipment (PPE);

- Knowledge of early warning alerts in case of disasters.

Our goal was to examine and analyze the self-evaluation of the respondents on their knowledge and skills for protection in the event of disasters. The availability of the necessary knowledge is in favor of preventive action and avoidance of health risks $[10,11]$.

Socio-demographic characteristics of the respondents. The study includes 322 workers in different spheres of the national economy in the Stara Zagora district.

The average age of the respondents was 43.15 years (range 21 - 68 years, SD - 10.018). The minimum age is 21 years and the maximum age is 68 . The distribution by age groups shows that with the highest relative rate $-34.47 \%$ are the persons aged 35-44 years, followed by the persons at the age 45-54 years - with a relative rate of $32.92 \%$. The age group 25-34 years has a relative rate of $17.7 \%$ and the age between 55 and 64 years $-11.49 \%$. Under the age of 24 , there are 7 persons $-2.17 \%$ and over 65 years they are $4-1.24 \%$. The distribution by gender shows that 213 of the surveyed persons are men $-66.1 \%$ and women are 109 - $33.9 \%$, i.e. two-thirds of the respondents are male. The distribution by education shows that the highest relative rate of those with completed secondary education is $69.3 \%$, followed by higher education graduates - $23.0 \%$ and college education - $4.0 \%$. People with a low level of education are $3.7 \%$, including 10 respondents with primary and 2 without education (Table 1). 
Table 1. Socio-demographic characteristics of the respondents

\begin{tabular}{|l|c|}
\hline $\begin{array}{l}\text { Socio-demographic } \\
\text { characteristics }\end{array}$ & $\%$ (N) \\
\hline \multicolumn{2}{|c|}{ groups } \\
\hline up to 25 years & $2,2 \%(7)$ \\
\hline from 25 to 34 years & $17,7 \%(57)$ \\
\hline from 35 to 44 years & $34,5 \%(111)$ \\
\hline from 45 to 54 years & $32,9 \%(106)$ \\
\hline from 55 to 64 years & $11,5 \%(37)$ \\
\hline over 64 years & $1,2 \%(4)$ \\
\hline \multicolumn{2}{|c|}{ Education } \\
\hline male & $66,1 \%(213)$ \\
\hline female & $33,9 \%(109)$ \\
\hline & $0,6 \%(2)$ \\
\hline without education & $3,1 \%(10)$ \\
\hline primary & $69,3 \%(233)$ \\
\hline secondary & $4,0 \%(13)$ \\
\hline college & $23,0 \%(74)$ \\
\hline university & \\
\hline &
\end{tabular}

Professional characteristics of the respondents how long they have been working there and the position occupied by the respondents are examined. Of the surveyed group, $74.8 \%$ work in the manufacturing sphere of activity and $25.2 \%$ occupy an administrative position. The average time of working in the profession is 16.48 years (range from 1 - 46 years, SD - 10.717). The minimum time is 1 year and the maximum is 46 years. The distribution by groups shows that with the greatest relative rate $-27.3 \%$ are the respondents with work experience 11-25 years, followed by the respondents with work experience 6-10 years - 23.0\%, 21-30 years - 22.0\%. With work experience under 5 years are $16.5 \%, 31-40$ years $-10.2 \%$ and over $41-0.9 \%$ (Table 2).

Table 2. Professional characteristics of the respondents

\begin{tabular}{|c|c|}
\hline Professional characteristics & $\%(\mathbf{N})$ \\
\hline \multicolumn{2}{|c|}{ Occupied position } \\
\hline manufacturing & $74,8 \%(241)$ \\
\hline administrative & $25,2 \%(81)$ \\
\hline \multicolumn{2}{|c|}{ Work experience } \\
\hline up to 6 years & $16,5 \%(53)$ \\
\hline from 6 to 10 years & $23,0 \%(74)$ \\
\hline from 11 to 20 years & $27,3 \%(88)$ \\
\hline from 21 to 30 years & $22,0 \%(71)$ \\
\hline from 31 to 40 years & $10,2 \%(33)$ \\
\hline over 40 years & $0,9 \%(3)$ \\
\hline
\end{tabular}

\section{Conducting an evacuation.}

According to Art. 65, para. 2 pt. 8 of the Law on Disaster Protection temporary evacuation of the population is organized by the mayor of the municipality. In the disaster area and in local individual cases, evacuation events may be ordered by the head of the village. Temporary evacuation of the population is organized in case of danger of striking impact of secondary factors such as half-destroyed and dangerous buildings, fires, flooded with industrial poisons and others [12].

An organized evacuation of people is done by evacuation assembly points (EAP), evacuation centers (EC) and places for accommodation (PA), creating the optimal organization for successful implementation of the measures for the protection of people and property. Places that are used for placement of evacuation assembly points are open areas that are not close to buildings, power lines, water currents. There are also organized temporary posts for the supply of food, water, medicines, warming drinks, clothes and blankets.

Knowledge of escape routes and the evacuation point are essential elements of evacuation measures as a mean of protection in disaster situations.

To the question "Are you familiar with escape routes specified in the action plan at a disaster of the structure in which you work" $90.68 \%$ of respondents answered positively. The remaining $9.32 \%$ did not have the training for temporary evacuation if necessary (Fig. 1).

Fig. 1. Self-evaluation of the knowledge about the route of evacuation.

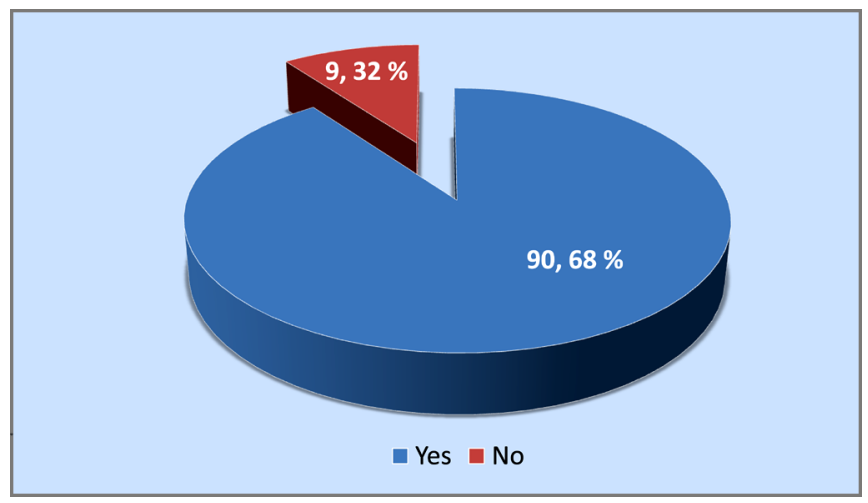

To the question "Do you know where is the indicated in the plan for evacuation - the evacuation assembly point for the structure in which you work?" majority of respondents $-81.99 \%$ answered positively, and $18.01 \%$ gave a negative answer (Fig. 2). 
Fig. 2. Self-evaluation of the knowledge about evacuation assembly point

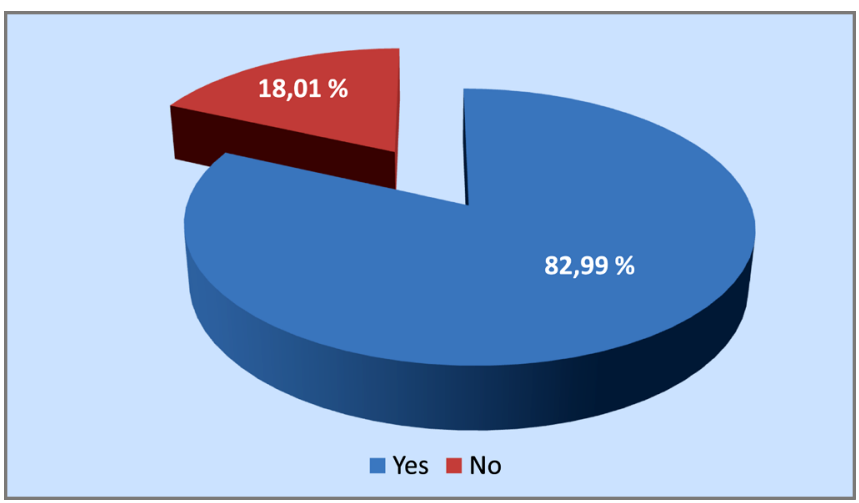

Use of Personal Protective Equipment (PPE). One of the main ways to protect the population in case of a disaster is the use of Personal Protective Equipment. They are divided to:

- The measures for protection the facial and respiratory system - filtering and respiratory protection, etc.;

- Means to protect the skin;

- Medical measures for protection - antidotes, radioprotectant vaccines, serums;

Individual measures for protection are stored in the warehouses of the General Directorate "Fire Safety and Civil Protection" within the respective districts and municipalities. In the event of a disaster situation, on the instructions from the Permanent regional or municipal commissions these funds are distributed to the population by teams of Main Directorate "Fire Safety and Civil Protection". In the Plan for Disaster Protection of Stara Zagora mayors are intended to provide protective equipment to the population if their distribution is necessary. It was found that municipalities do not have the personal resources to protect the population from industrial poisons [13].

Self-assessment of the respondents on the required knowledge about the effectiveness and need for the use of individual protection in disasters is presented in Fig. 3. $47.52 \%$ evaluate their knowledge as enough, $45.65 \%$ need additional knowledge and $-6.83 \%$ do not have the knowledge.

Fig. 3. Self-evaluation of knowledge about individual measures of protection.

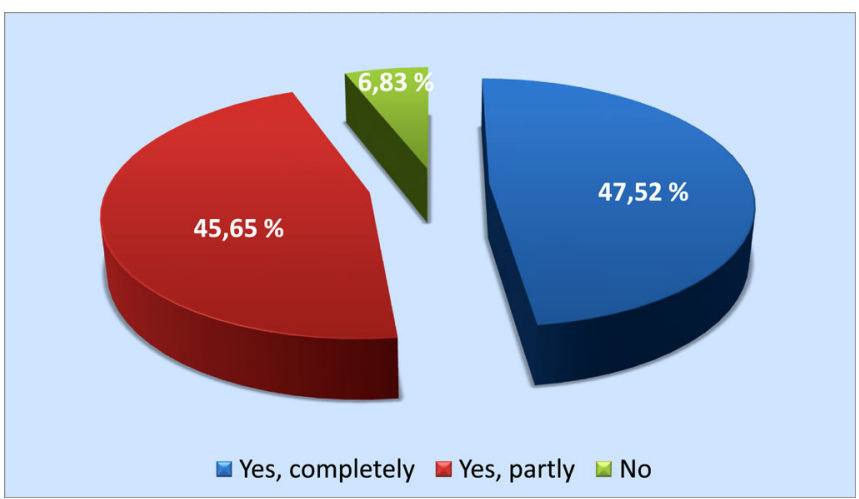

To the question "Are you aware of the rules for selecting suitable for you mask and proper placement?" More than half of respondents $-52.17 \%$ replied that they were fully aware, $32.92 \%$ are partly aware, $14.91 \%$ are not aware (Fig. 4).

Fig. 4. Self-evaluation of the knowledge about the rules of selection and proper placement of the mask

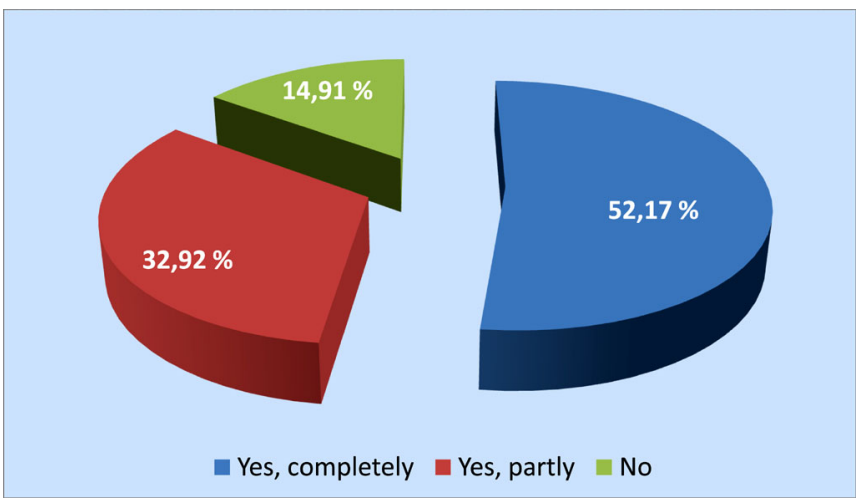

Knowing the signals for early warning and alert in case of disasters. Informing the population about emergencies arising shall be done by the decision of the Permanent Committee for protection of the population in case of disasters, accidents and catastrophes as a part of Council of Ministers and in the regions and the municipality by the local committees [14].

The primary responsibility of the Main Directorate of "Fire Safety and Population Protection" is a timely warning of the population in case of a disaster situation. For that purpose on the state territory, one united warning system is built and maintained in readiness. It includes [15]:

- a siren system providing acoustic coverage throughout the country;

- national broadcasting system on Bulgarian National Television, Bulgarian National Radio, as well as regional radio;

- local radio stations.

Furthermore, in adjacent areas of NPP "Kozloduy" and the sites working with industrial poisons are built local alert systems.

The technical state of the national warning system is continuously monitored by the authorities of the General Directorate "Fire Safety and Population Protection" and the Committee of Posts and Telecommunications.

Warning of the organizations for control, forces and measures of the population in an emergency situation is done via signals of Main Directorate "Fire Safety and Population Protection".

Analysis of the data from our study shows that $36.96 \%$ of respondents are aware of the signals of the Main Directorate "Fire Safety and Population Protection". More than half - 54.04\% need additional knowledge, and 9,01\% do not have the knowledge (Fig. 5). 
Fig. 5. Self-evaluation of the knowledge about the signals of early warning and disaster alert

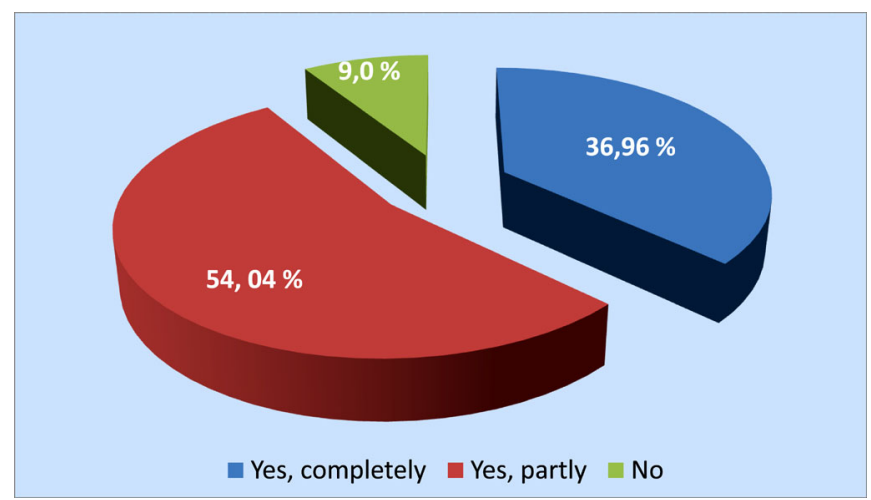

In the study of self-assessment of knowledge and skills for protection in emergency situations, the question put to each of the respondents was: "Do you think you have the necessary knowledge and skills for protection in emergency situations?" The answers to the questions have the following distribution: $23.6 \%$ consider that they have fully proficient knowledge and skills; $65.53 \%$ define their skills and knowledge as insufficient; 10.87 percent - do not have the knowledge and necessary skills (Fig. 6).

Fig. 6. "Do you think you have the necessary knowledge and skills for protection in emergency situations?"

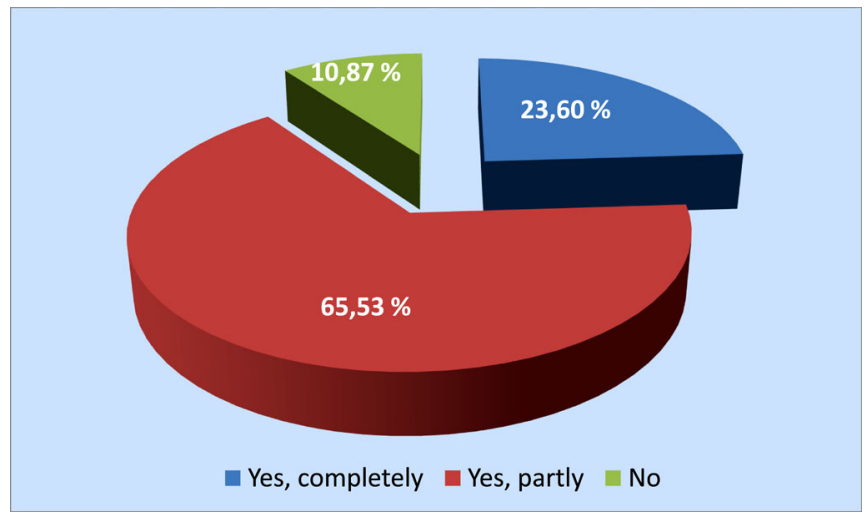

Self-assessment of the respondents in this matter shows that there is a statistically significant difference by gender by Fisher's Exact Test $(\mathrm{P}=0.002)$. Women in significantly higher percentage believe they have the necessary knowledge and skills for protection in emergency situations (Fig. 7).

Fig. 7. Self-assessment of knowledge and skills for disaster protection according to the gender

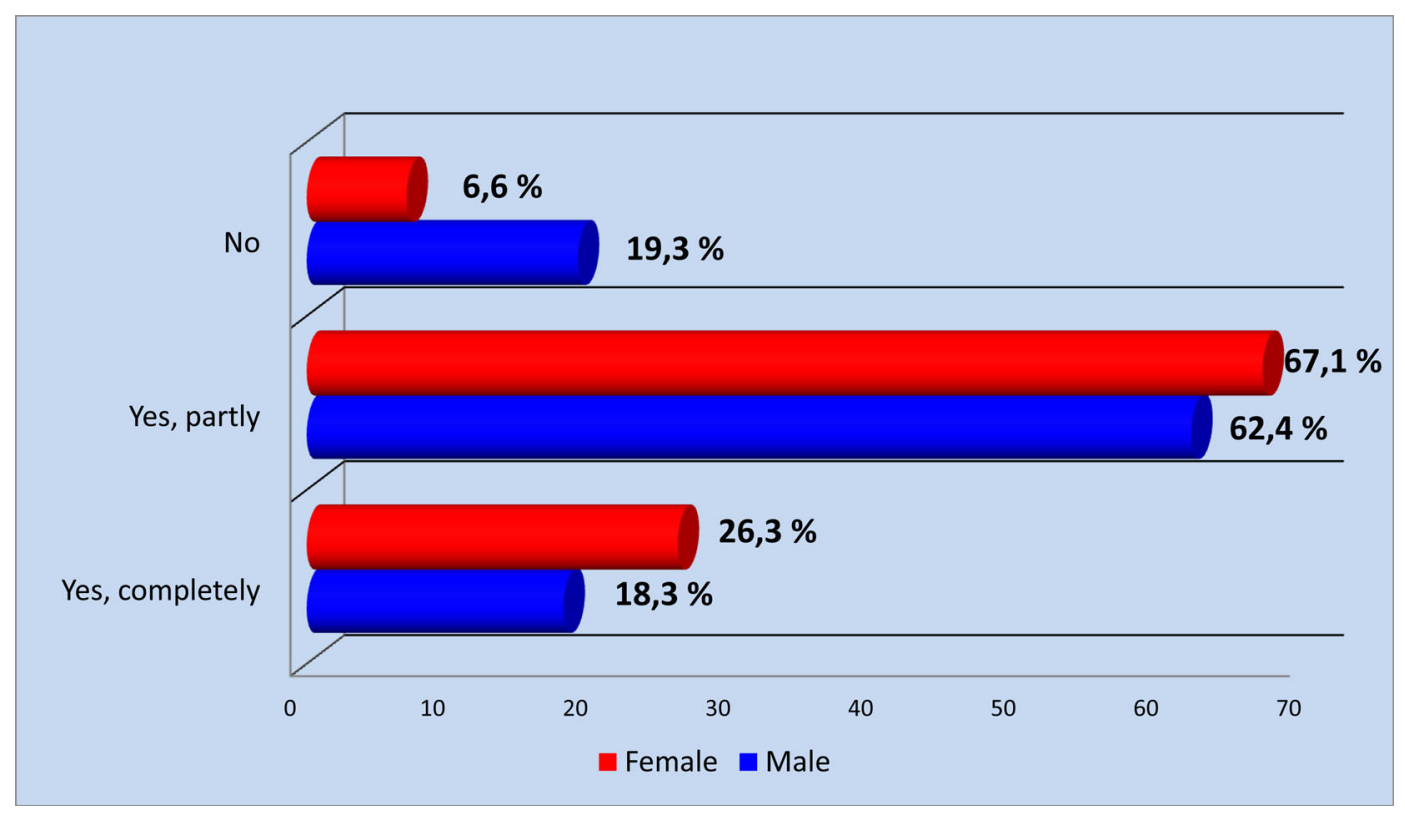

The exact criterion Fisher shows that there is a statistically significant correlation between self-assessment of respondents' knowledge and skills about protection and available at the time of survey knowledge and skills to:

- signals for early warning and alert in case of the occurrence of emergency situations $(\mathrm{P}<0.0001)$;

- effectiveness and necessity of the use of individual and collective protection measures $(\mathrm{P}<0.0001)$;

- rules for the selection of mask and its proper placement $(\mathrm{P}<0.0001)$;

- route and assembly point of evacuation ( $\mathrm{P}$ $<0.0001)$.
There is a significant correlation between self-esteem and the knowledge and skills of respondents in all the elements of protection. The percentage of mismatch ranges from 0.1 to $6.6 \%$

It was found a statistically significant correlation between self-assessment of respondents' knowledge and skills to protect and sources for acquiring this knowledge and skills $(\mathrm{P}<0.0001$ for training courses, $\mathrm{P}=0.006$ for media). A large percentage of the respondents indicated that they have the necessary knowledge and skills (94.7\%). The Primary source for acquiring their training are the educational courses. The media as a source of knowledge and 
skills is specified by respondents who believe that they lack the necessary skills $(68.6 \%)$.

The exact criterion of Fisher shows that there is a statistically significant correlation between self-assessment of respondents' knowledge and skills about protection and the ways you need to acquire more of that knowledge ( $\mathrm{P}=$ 0.006 for training courses, $\mathrm{P}=0.003$ for brochures, flyers). Training courses occupy a leading place among the preferred ways of acquiring knowledge and skills (Table 3).

Table 3. Correlation between the self-assessment of knowledge and skills about protection and preferred sources for acquiring knowledge and skills

\begin{tabular}{|c|c|c|c|}
\hline $\begin{array}{c}\text { How should you acquire more } \\
\text { knowledge and skills for disaster } \\
\text { protection? }\end{array}$ & \multicolumn{2}{|c|}{$\begin{array}{c}\text { Do you think you have the necessary knowledge and skills } \\
\text { for disaster protection? }\end{array}$} \\
\cline { 2 - 4 } $\begin{array}{c}\text { Yraining courses } \\
\text { Trochures, leaflets }\end{array}$ & $92,1 \%$ & Yes, partly & No \\
\hline Brochely & $25,0 \%$ & $40,1 \%$ & $5,6 \%$ \\
\hline
\end{tabular}

\section{DISCUSSION}

The nature of the consequences of possible emergency situations requires a willingness to use all ways and means to protect the population and national economy and conducting preliminary activities to prevent and reduce the harmful effects. Priority activities for disaster protection is the formation of state policy for public education, including leaders, learners, respondents and volunteers.

The analysis of the socio-demographic characteristics in our study shows that there is age diversity, but the predominant group of respondents are aged 35-44 years $(34.47 \%)$. Prevails male sex - $2 / 3$ of surveyed persons, which is explained by the fact that the survey was conducted mainly among workers in heavy industry enterprises. The vast majority of them $-74.8 \%$ are working in the manufacturing sphere. The study is aimed at actively working people at enterprises and companies in various industries in the Stara Zagora district because the risk of manmade disasters at their workplace is significant. For this reason, some of the factories and companies are included in the list of objects from the critical infrastructure of the Republic of Bulgaria. Moreover, in case of man-made disasters occurring in these enterprises, workers there are the first ("first responders") to be involved in the organization of protective measures and first aid to the injured people. All this necessitate continuous and purposeful training on the means of protection and self-defence and timely information.

\section{CONCLUSION}

Insufficient public awareness on the principles, goals, objectives and activities for protection before, during and after disaster situations represents a major challenge. So far, the measures implemented in this regard are inconsistent and limited in scope. There is a need to improve the knowledge and skills about protection in emergency situations by conducting theoretical training and increasing the efficiency of this training.

\section{ACKNOWLEDGEMENTS}

This study was supported by the Trakia University, Stara Zagora, Bulgaria with scientific research project „Readiness of the population for protection from disasters and providing of first medical aid and veterinary medical aid“, 17/2016, funded by Ministry of Education. We express our gratitude to Faculty of Medicine Stara Zagora, Bulgaria and we also acknowledge the support of Bulgaria Red Cross - Stara Zagora, Civil Defence of Municipality - Stara Zagora, and CIMIC Bulgaria, and Occupational Medicine Service "Magivan” Stara Zagora.

\section{REFERENCES:}

1. Janackovic G, Vasovic D, Nikolic J, Musicki S, Vranjanac Z. Vulnerability assessment of municipality areas to natural disasters based on group fuzzy analytic hierarchy process. JEPE. 2018； 19(4):1526-1535. [nternet]

2. Dimitrova D, Slavova V, Mihailova Il. Medical provision for the population in disaster situation in Bulgaria - traditions and current tendencies. General Medicine. 2015; 17(2):9-16. [in Bulgarian]

3. Papatheodorou K, Klimis N,
Margaris B, Ntouros K, Evangelidis K, Konstantinidi A. An Overview of the EU Actions towards Natural Hazard Prevention and Management: Current Status and Future Trends. JEPE. 2014; 15(2):433-444. [Internet]

4. Slavova V, Parashkevova B, Ivanov V, Dimitrova D, Karaslavova E. [Protection of the population and providing humanitarian aid in disastrous situation - European policy.] General Medicine. 2014; 16(4):18-22. [in Bulgarian]

5. Annual Report on the European
Union's humanitarian aid and civil protection and their implementation in 2017. EC. Brussels, 30.11.2018. COM (2018) 774 final. [Internet]

6. European Commission. General Guidelines on Operational Priorities for Humanitarian Aid in 2020. EC. Brussels, 21.11.2019. SWD(2019) 421 final. [Internet]

7. European civil protection and humanitarian aid operations. EU Civil Protection Mechanism. EC. Brussels, 2020. [Internet]

8. Council of Europe. Decision 
${ }^{1} 1313$ /2013/ EU of the European parliament and of the council on a Union Civil Protection Mechanism. Official Journal of the European Union. 20. 12. 2013: L347-924. [Internet]

9. Mihailova Il, Todorova D. [Organization of protection of the population in disaster situations. Disaster medicine.] Medical Publishing - Arso, Sofia. 2011; 390-395 p. [in Bulgarian]

10. Paskaleva T. Researching the level of informing of elderly people about the health prevention and pro- phylactics. ARTTE. 2016; 4(4):331336. [Internet]

11. Paskaleva T, Dragusheva S. Research of the behavioral risk factors with elderly people in the context of the contemporary vision for health promotion. ARTTE. 2017; 5(3):231237. [Internet]

12. Disaster Protection Act. State Gazette of the Republic of Bulgaria. Sofia, Bulgaria. 19/12/2006; 102:217. [in Bulgarian] [Internet]

13. Plan for Disaster Protection of
Stara Zagora. Order RD-09-185/18. 04. 2012 of the District Governor of Stara Zagora. Stara Zagora, Bulgaria, 2012. [in Bulgarian]

14. National Plan for Disaster Protection. Council of Ministers, Sofia, Bulgaria. 2010. [in Bulgarian] [Internet]

15. [National Program for Disaster Protection 2014-2018.] Council of Ministers, Sofia, Bulgaria. 2013. [in Bulgarian] [Internet]

Please cite this article as: Slavova V, Ivanov V, Taleva P, Petrova-Tacheva V. Study of Civil Protection readiness in case of disasters. J of IMAB. 2020 JOct-Dec;26(4):3356-3362. DOI: https://doi.org/10.5272/jimab.2020264.3356

Received: 17/05/2019; Published online: 02/10/2020

\section{Address for correspondence:}

Vanya Slavova,

Department Neurology, Psychiatry and Disaster medicine, Faculty of Medicine, Trakia University, Stara Zagora,

11, Armeyska Str., 6000 Stara Zagora, Bulgaria.

E-mail: vslavova71@yahoo.com, 